\title{
Anti-estrogen therapy for hereditary hemorrhagic telangiectasia - a long-term clinical trial*
}

\author{
Eitan Yaniv, Michal Preis, Jacob Shvero, Ben Nageris, Tuvia Hadar
}

Nose and Sinus Institute, Department of Otorhinolaryngology, Rabin Medical Center, Beilinson Campus, Petah Tiqwa and Sackler Faculty of Medicine, Tel Aviv University, Tel Aviv, Israel

\begin{abstract}
SUMMARY Statement of problem: Hereditary hemorrhagic telangiectasia (HHT) is associated with recurrent epistaxis in $90 \%$ of the cases. Good response to hormone treatment has been documented, although its use remains controversial. The aim of this study was to examine the efficacy of an anti-estrogenic agent, tamoxifen, in the treatment of HHT-associated epistaxis.

Method of Study: Out of 46 patients with diagnosis of epistaxis due to HHT who started treatment with tamoxifen $20 \mathrm{mg} / \mathrm{d}$, 38 patients completed a mean of 23.4 months of treatment. All patients filled out a self-assessment questionnaire of rhinologic Quality of Life and epistaxis grading scale.

Main Results: The bleeding score and the Quality of Life score improved. Hemoglobin concentration also improved. None of the patients needed blood transfusions during the treatment period. Only one patient had minor side effects of the drug.

Principal Conclusions: Tamoxifen appears to be an effective agent for the treatment of epistaxis due to HHT.
\end{abstract}

Key words: Tamoxifen, HHT, epistaxis, nasal bleeding

\section{INTRODUCTION}

Hereditary hemorrhagic telangiectasia (HHT), also known as Osler-Weber-Rendu disease ${ }^{(1,2)}$, is an autosomal dominant blood vessel disorder that leads to localized angiodysplasia ${ }^{(3)}$. HHT has a general prevalence of $1 / 10,000$ in Caucasians ${ }^{(4)}$. Ultrastructural analyses have failed to demonstrate a unique pathological abnormality. Proposed etiologies include endothelial cell degeneration, defects in endothelial junctions, lack of elastic fibers with incomplete smooth muscle coating of the vessels, and weak connective tissue surrounding the vessels (5). HHT has been linked to mutations in the endoglin (ENG) gene (HHT1) or the ACVRL1/ALK1 gene (HHT2). Recently, several other genes were found to play a role (MADH4/JPHT/ BMPRH/PPH; HHT3) ${ }^{(6-8)}$. However, a positive finding on DNA sequencing has not yet been included among the accepted diagnostic criteria ${ }^{(8)}$.

Recurrent epistaxis is the most common presenting symptom of HHT, occurring in more than $90 \%$ of patients ${ }^{(9)}$. Telangiectasia may also be present ( $64 \%$ of patients) in the skin, conjunctivae, oral cavity, pharynx, and gastrointestinal tract. Less common but more serious manifestations include arteriovenous malformations (48\%), intracranial $(9 \%)$ or pulmonary (15\%) aneurysms, progressive liver disease (atypical cirrhosis), and high-output cardiac failure ${ }^{(10,11)}$.

The treatment of epistaxis in HHT poses a challenge because routine measures such as cautery and packing may actually exacerbate the bleeding and rarely lead to a durable response ${ }^{(9)}$. The disease progresses with time in more than $50 \%$ of cases ${ }^{(12)}$, prompting aggressive treatment measures such as laser photocoagulation, septodermoplasty, intranasal forehead flaps, complete nostril closure, embolization of the nasal vasculature, arterial ligation, and brachytherapy ${ }^{(9,10,13,14)}$.

Recently, we published a double-blind placebo-controlled clinical trial on the efficacy of the antiestrogen drug, tamoxifen $20 \mathrm{mg} /$ day, for the treatment of epistaxis in HHT ${ }^{(15)}$, with good results. The aim of the present study was to report the long-term effects of tamoxifen in patients with epistaxis associated with HHT.

\section{MATERIAL AND METHODS}

Treatment of patients

From February 2005 to February 2009, 46 patients at our center started treatment with tamoxifen $20 \mathrm{mg}$ /day for severe 
Table 1. Mean bleeding score, quality of life score, and hemoglobin level in patients with epistaxis due to hereditary hemorrhagic telangiectasia before and after treatment with tamoxifen.

\begin{tabular}{llccc}
\hline Measure & No. & $\begin{array}{c}\text { Pretreatment value } \\
\text { (mean } \pm \text { SD, range) }\end{array}$ & $\begin{array}{c}\text { Post-treatment value } \\
\text { (mean } \pm \text { SD, range) }\end{array}$ & p value \\
\hline Severity score & 38 & $5.7 \pm 1.8(3-9)$ & $3.8 \pm 1.6(0-7)$ & $0.0001^{*}$ \\
Quality of life score & 38 & $78.8 \pm 30.9(37-147)$ & $63.5 \pm 27.6(32-143)$ & $0.0001^{*}$ \\
Hemoglobin $(\mathrm{gr} / \mathrm{dl})$ & 34 & $10.6 \pm 2.9(2.5-14.9)$ & $11.9 \pm 2.5(4-15.2)$ & $0.0001^{\dagger}$ \\
\hline *Wiloxon & & &
\end{tabular}

*Wilcoxon signed ranks test

$\dagger$ Paired t-test

epistaxis due to HHT. All met at least 3 of the 4 established criteria for diagnosis ${ }^{(8)}$. Patients were examined every 3 months in the first year of treatment and every 6 months thereafter. At onset of treatment and at every follow-up visit, blood was collected to determine blood count, clotting time, and kidney and coagulation function. All female patients were referred for gyneacological evaluation every 6 months. In addition, at the first visit before treatment and at conclusion of the present study, in May 2009, the patients were asked to complete the Rhinosinusitis Disability Index ${ }^{(16)}$, which is used to evaluate disease severity and rhinological quality of life. For disease severity, patients are requested to grade 3 items that refer to his or her condition during the previous month as follows:

1. Intensity of bleeding (none - 0 ; slight/few drops -1 ; mild/ significant -2 ; severe/hard to control -3 ).

2. Frequency of bleeding (none $-0 ; 1-5$ episodes of epistaxis 1; 6-10 episodes -2 ; $11-29$ episodes -3 ; daily -4$)$

3 Blood transfusions (none -0 ; one -1 ; more than one -2 ).

Quality of life is scored on a scale of 1 to 5: the lower the score, the better the quality of life ${ }^{(16)}$.

The study was approved by the ethics committee of Rabin Medical Center.

\section{Statistical analysis}

The data are presented as mean \pm standard deviation. The Wilcoxon signed ranks test was used to compare the epistaxis and quality of life scores before and after treatment, and the paired t-test was used to compare hemoglobin levels at the same time points. All reported $\mathrm{p}$ values are two-sided; $\mathrm{p}<0.05$ was considered statistically significant. For the statistical analyses, we used SPSS 15.0.1 software (SPSS Inc., Chicago, IL, USA).

\section{RESULTS}

Of the total 46 patients who started treatment with tamoxifen, $8(17 \%)$ dropped out of the study prior to its termination. This included 2 patients who improved and experienced no deterioration in their condition on stopping treatment; 1 patient (female) with ultrasonic mucosal hypertrophy of $11 \mathrm{~mm}$ which resolved when she tapered treatment (no biopsy taken); 3 patients who did not improve with treatment; and 2 patients who were advised to discontinue the study by their family physician because tamoxifen is not licensed for the treatment of HHT. Other than mucosal changes, none of these patients had adverse drug effects.

The remaining 38 patients included 20 men and 18 women of mean age $52.9 \pm 13.5$ years. All completed the questionnaires at both time points. The duration of follow-up for the whole group was 3 - 50 months (mean $23.4 \pm 16.0$ months).

The results of the outcome measures are shown in Table 1 . At onset of treatment, disease severity was scored 2-3 by all patients. All had had at least 6 episodes of epistaxis in the last month; 29 had had at least 11 episodes, including 18 with daily bleeding. Seven patients had received blood transfusions ( 1 to 3 units) in the last month. By the end of the treatment, the mean bleeding score for the study group decreased from $5.7 \pm 1.8$ to $3.8 \pm 1.6(\mathrm{p}=0.0001)$, and the mean hemoglobin level improved from $10.6 \pm 2.9$ to $11.9 \pm 2.5 \mathrm{gr} / \mathrm{dl}(\mathrm{p}=0.0001)$. None of the patients required blood transfusions during the treatment period. The mean quality of life score decreased (improved) from $78.8 \pm 30.9$ before treatment to $63.5 \pm 27.6$ after $(p=0.0001)$. None of the patients who completed the study reported side effects from treatment.

\section{DISCUSSION}

The present study extends our earlier six-month-long doubleblind placebo-controlled trial ${ }^{(15)}$ investigating the efficacy of tamoxifen in the treatment of epistaxis associated with HHT. We included 21 patients from the earlier study and 25 patients who started treatment after the first trial ended.

Clinically, HHT is a severe and chronic systemic disease that considerably impacts on patient quality of life. Owing to the recurrent epistaxis, patients are afraid to leave home or to travel ${ }^{(19)}$. Some have severe anemia and require blood transfusions ${ }^{(5,11)}$. HHT may also present in other body areas, causing gastrointestinal bleeding, aneurysms, hepatic bleeding with progressive liver disease (atypical cirrhosis), and high-output cardiac failure ${ }^{(9,10)}$. Preliminary reports indicate that bevacizumab is very effective in the treatment of HHT, especially in the presence of arteriovenous-malformations and severe organ failure ${ }^{(20-23)}$. To the best of our knowledge, other than bevacizumab, there is no other effective treatment. The use of nasal packing, coagulation, and surgery for the nasal epistaxis may cause scarring and narrowing of already blocked airways. In our series, 22 patients had blocked nasal airways and 4 had nasal septal perforations.

The subjective outcome measures in the present study consisted of self-reported epistaxis and rhinologic quality-of-life scales, completed at onset of treatment and at the end of the study, in May 2009. We found that in most patients, the epistaxis decreased in severity and frequency, and the qual- 
ity of life improved. The changes in the mean group scores on both scales were statistically significant. Hemoglobin concentration improved as well. There were almost no side effects of treatment; one patient who failed to complete the trial had uterine mucosal hypertrophy. None of the patients required a blood transfusion during treatment. These findings suggest that tamoxifen is a useful treatment modality for patients with severe epistaxis associated with HHT.

\section{CONCLUSION}

The present long-term clinical trial indicates that tamoxifen $20 \mathrm{mg} / \mathrm{d}$ is effective for the treatment of epistaxis due to HHT, with almost no adverse effects.

\section{REFERENCES}

1. Hanes FM. Multiple hereditary telangiectasia causing hemorrhage (hereditary hemorrhagic telangiectasia). Bull Johns Hopkins Hosp. 1909; 20: 63-75.

2. Gibbs DD. Rendu-Osler-Weber disease: a triple eponymous title lives on. J R Soc Med. 1986; 79: 742-743.

3. Haitjema T, Westermann CJ, Overtoom TT, et al. Hereditary hemorrhagic telangiectasia (Osler-Weber-Rendu disease): new insights in pathogenesis, complications and treatment. Arch Intern Med. 1996; 156: 714-719.

4. Guttmacher AE, Marchuk DA, White RI Jr. Hereditary hemorrhagic telangiectasia. N Eng J Med. 1995; 333: 918-924.

5. Assar OS, Friedman CM, White RI Jr. The natural history of epistaxis in hereditary hemorrhagic telangiectasia. Laryngoscope 1991; 101: 977-980.

6. Pau H, Carney AS, Walker R, et al. Is oestrogen therapy justified in the treatment of hereditary haemorrhagic telangiectasia: a biochemical evaluation. Clin Otolaryngol. 2000; 25: 547-550.

7. Bergler W, Sadick H, Gotte K, et al. Topical estrogens combined with argon plasma coagulation in the management of epistaxis in hereditary hemorrhagic telangiectasia. Ann Otol Rhinol Laryngol. 2002; 111: 222-228.

8. Shovlin CL, Guttmacher AE, Buscanini E, et al. Diagnostic criteria for hereditary hemorrhagic telangiectasia (Rendu-Osler-Weber syndrome). Am J Med Gen. 2000; 91: 66-67.

9. Shah RK, Dhingra JK, Shapshay SM. Hereditary hemorrhagic telangiectasia: a review of 76 cases. Laryngoscope 2002; 112: 767773.

10. Pau H, Carney AS, Murty GE. Hereditary hemorrhagic telangiectasia (Osler-Weber- Rendu syndrome): otorhinolaryngological manifestations. Clin Otolaryngol. 2001; 26: 93-98.

11. Larson AM. Liver disease in hereditary hemorrhagic telangiectasia. J Clin Gastroenterol. 2003; 36: 149-158.
12. Reilly PJ, Nostrant TT. Clinical manifestations of hereditary hemorrhagic telangiectasia. Am J Gastroenterol. 1984; 79: 363-367.

13. Shapsay SM, Oliver P. Treatment of hereditary hemorrhagic telangiectasia by Nd-YAG laser photocoagulation. Laryngoscope 1984; 94: 1554-1556.

14. Pohar S, Mazeron JJ, Ghilezan M, et al. Management of epistaxis in Rendu-Osler disease: is brachytherapy effective? Int J Radiat Bio Phys. 1993; 27: 1073-1077.

15. Yaniv E, Preis M, Hadar T, et al. Anti-estrogen therapy for hereditary hemorrhagic telangiectasia - a double-blind placebocontrolled clinical trial. Laryngoscope 2009; 119: 284-288.

16. Al-Deen S, Bachmann-Harildstad G. A grading scale for epistaxis in hereditary haemorrhagic teleangectasia. Rhinology 2008; 46: 281-284.

17. Birch DS, Saleh HA, Wodehouse T, et al. Assessing quality of life for patients with chronic rhinosinusitis using the "Rhinosinusitis Disability Index". Rhinology 2001; 39: 191-196.

18. Jameson JJ, Cave DR. Hormonal and antihormonal therapy for epistaxis in hereditary hemorrhagic telangiectasia. Laryngoscope 2004; 114: 750-759.

19. Vase P. Estrogen treatment of hereditary hemorrhagic telangiectasia. Acta Med Scand. 1981; 209: 393-396.

20. Mitchell A, Adams LA, MacQuillan G, et al. Bevacizumab reverses need for liver transplantation in hereditary hemorrhagic telengiectasia. Liver Transpl 2008; 14: 210-213.

21. Bose P, Holter JL, Selby GB. Bevacizumab in hereditary hemorrhagic telangiectasia. N Engl J Med. 2009; 360: 2143-2144.

22. Oosting S, Nagengast W, De Vries E. More on bevacizumab in hereditary hemorrhagic telangiectasia. N Engl J Med. 2009; 361: 931.

23. Flieger D, Hainke S, Fischbach W. Dramatic improvement in hereditary hemorrhagic telangiectasia after treatment with the vascular endothelial growth factor (VEGF) antagonist bevacizumab. Ann Hematol. 2006; 85: 631-632.

Eitan Yaniv, MD

Nose and Sinus Institute

Department of Otorhinolaryngology

Rabin Medical Center

Beilinson Campus

Petah Tiqwa 49100

Israel

Tel: +972-3-937-6450

Fax: +972-3-937-6467

E-mail: docyaniv@yahoo.com 